\title{
Paradigm Shifts in Geographical Research and Geospatial Applications
}

\author{
Koyel Paul \\ Vibhash Chandra Jha ${ }^{2}$
}

\begin{abstract}
Keywords:
Geographical research

Geospatial applications

Social sciences

Paradigm

Paradigm shift

Abstract

Geography enlightened a vast area of social sciences. It consists earth's land and ocean surface, different landforms and their formation, evolution, subsurface phenomena, atmosphere and related activities, environment and its attributes, environment as a habitat of living elements as well as a human being and their reciprocal relationships in a very critical and analytical approach. From the inception of geography as a separate discipline, it evolved through its versatile, comprehensive and holistic nature. Alteration and modification change its nature through space and time. And accordingly, the established paradigm always changed depending on the demand of the geographers. This paper highlighted specifically the paradigm shift in geographical research with special reference to geospatial applications. Geography has two basic aspects, Pure and Applied. Recent trend shows that most of the geographical research is focused on the applied field rather than the pure aspects of the subject itself. The most interesting fact is that the applied research is basically depends upon the Geospatial technology. A distinct paradigm shifts have been taking place in both the Geographical Research and the Geospatial Technology through Digitalization. The large growing population of the world require a logical and scientific shift in both pure and applied research in the domain of geography. Particular mention may be made in the fields of Geography such as geomorphology, population geography, urban geography, rural development and environmental geography. This paper also highlights the major paradigmn shifts in the behavioural geography, systematic geography, regional geography, medical geography, geospatial sustainability and cartography from paper map to digital map. It is now established that no discipline can survive without adopting a new strategy and technology.
\end{abstract}

${ }^{1}$ Birbhum Mahavidyalaya University of Burdwan. Departament of Geography, Suri, India. koyel12geo@ gmail.com ${ }^{2}$ Visva-Bharati University.Department of Geography,Santiniketan, Índia. vcjha@asia.com 


\section{INTRODUCTION}

Geography has very diversified nature. From its origin time to recent dimensions, it has been changing in its nature, content, scope and applications. The main concern of this paper is the recent focus and enlightenment of geographical research in the $21 \mathrm{st}$ century. Since, 15th century, geographical research has changed its nature towards quantification for the interest of accuracy in the results. Geographical research has got its two basic dimensions i.e. pure geographical research and applied geographical research. It is noted that there is a major change in pure geographical research upto19th century. Thereafter the trend of geographical research has been moving towards the applied geography. It is mainly due to the induction of modern techniques. Its effects have been visualized on the basic research also but a larger part is towards the applications to address the society problems that are relating to livelihood.

Change is the most permanent and reliable feature in this universe. It is inevitable for all living and nonliving components of the earth. The dynamism of human being is more consistent. Maybe it is biological or psychological but the evolution is mandatory for sustenance. As far as, the behavioural pattern is concerned, we can notice the changes in food habits, tests, cooking processes, dressing sense, dress material, festivals, social behaviour, etc. These changes can be detected from individual to the community through generations. It is the first and unavoidable rule of nature.

Knowledge is also dynamic. The content of knowledge, the way to gather the information for knowledge, the process of storage, the way of its applicability is also changed according to time and perspective. That is why any discipline has to keep changing temporarily. The scope, contents and approaches are continuously evolved. Geography is not an exception from evolution.

With the advent of Remote Sensing, Geographical Information System (G.I.S.) and Geographical Positioning System (G.P.S.), the geospatial applications have acclaimed the significant change in geographical research. Since last six decades, it has been noted that there is a paradigm shift in geographical research from fundamental to societal. Various international schools of thoughts have shown with their publications in their respective interests. These lead to the development of different schools of belief systems in geography.

Any discipline or sub-discipline thereof, always functions and proceeds within a framework or some conceptual matrices, called 'paradigms'. Paradigm focuses on the philosophical perspective and methodologies that have been in vague and which continue to provide the theoretical feedback for the new researchers. Any model, idea, concept, technique or method that is capable of generating scholarly concern or research in a particular time period may be called a paradigm (RANA, 2008).
No discipline can survive without having a paradigm shift. It applies to geography also. Paradigms have the capacity to change the thinking, outlook and ideology of the people. The core of Geographical researches is the study of the relationship between people and environment. The paradigm changes in research have followed global and national priority of social needs and justice in different decades.

Development of geographical thoughts or concepts such as Determinism (environmentalism), Possibilism, Neo-determinism, etc are the manifestation of different paradigm phases in since the classical period of Geography. These geographical thoughts or concepts are still considered in geographical research as these reflect the changing views of man- environmental relationships and uses of resources with different contemporary geographical techniques in different decades.

Recent paradigms in geography are much blended with traditional and modern geographical concepts, quantitative- multidisciplinary approaches and larger application of geospatial data.

\section{Paradigm}

A paradigm describes-

i) What is to be observed and scrutinised?

ii) The kind of questions that are supposed to be asked and probed for answers in relation to this subject.

iii) How these questions are to be structured?

iv) How the results of scientific investigations should be interpreted?

v) What is the stability of the assumption have been made?

\section{Aims and Objectives:}

This paper describes paradigms shifts regarding geographical concepts and research approaches with the applications of geospatial techniques and their extent in different types of researches as evolved due to paradigm shift. It also tries to make an attempt to predict the future thrust of geographical research.

\section{Kuhn's Model and Paradigm}

The term paradigm was coined by S. Thomas Kuhn (1922-1996), an American historian of science, while postulating a very important theory about the growth and development of science. Kuhn (1962) defined 'paradigm' as the entire constellation of beliefs, values, and techniques, and so on shared by the members of a given community.' According to Kuhn, science is not a well-regulated activity where each generation automatically builds upon the results of the earlier workers. Every subject has to face several crisis periods along with a steady and smooth state of zdevelopment during its growth. He further defined paradigm as "universally recognized scientific achievements that for 
a time provide model problems and solutions to a community of practitioners".

The Kuhn Cycle is a simple cycle of progress described by Thomas Kuhn in 1962 in his seminal work The Structure of Scientific Revolutions. In Structure Kuhn challenged the world's current conception of science, which was a steady progression of the accumulation of new ideas. In a brilliant series of reviews of past major scientific advances, Kuhn showed this viewpoint was wrong. Science advanced the most by occasional revolutionary explosions of new knowledge, each revolution triggered by introduction of new ways of thought so large they must be called new paradigms. From Kuhn's work came the popular use of terms like "paradigm," "paradigm shift," and "paradigm change." The Kuhn Cycle is preceded by the Prescience step. After that the cycle consists of the five steps as shown. The Model Drift step was added to clarify the cycle and allow reuse of the Model Drift concept in the System Improvement Process. In the present day context, this needs modification keeping in mind the magnitude of the paradigm shifts in geographical research, need and application.

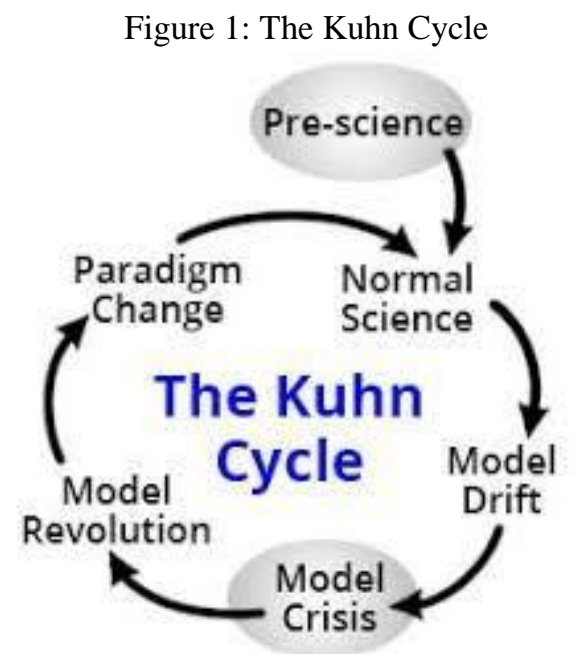

Source: T. Kuhn, 1962.

\section{Pre-science}

It is also known as the pre-paradigm phase. It is the prestep to the main Kuhn cycle. In pre-science yet there is not yet a model of understanding, it is not mature enough to solve the field's problems. The model maybe close, may be promising and thus be attracting plenty of followers. But it is not yet a real science that works.

\section{Normal Science}

It is the first step of Kuhn's cycle. This cycle was first described in Thomas Kuhn's seminal work, "The Structure of Scientific Revolutions" in 1962. Normal science means research firmly based upon one or more past scientific achievements that some particular scientific community acknowledges for a time as supplying the foundation for its further practice. (KUHN,1970)
Kuhn points out that Normal science, the activity in which most scientists inevitably spend almost all their time, is predicted on assumption that the scientific community knows what the world is like. Much of the success of the enterprise derived from the community willingness to defined that assumption if necessary at a considerable cost, normal science often suppresses fundamental novelties because they are necessarily subversive of its basic commitments.

\section{Model Drift}

If the field has recently been able to solve its biggest problem but is becoming less able to so, then the field is in the model drift stage. The understanding of the model, the approach towards problem-solving and the central paradigm-all these have drifted away from their normal ability to succeed. The best action in this time is the formalrealization of the deterioration of the paradigm and focussed on fixing it. The researcher's task is to define the paradigm in writing, make a model, or did whatever it takes to define it in detail, then determine why it is failing slightly, then repair the problem and return to normal science.

\section{Model Crisis}

In this the paradigm is unable to solve any problem of the discipline. The discipline cannot succeed through overcoming any emerging crisis. This is a crisis because accomplishing a mission has become impossible.

\section{Model Revolution}

In this step, the researcher is struggling to figure out a new way to forward the works and have viable candidates for a new paradigm. It takes considerable head-scratching, experimentation and input from many people. This is an extremely productive phase. This phase has the chance to throw out what does not work and replace it with what does. All sorts of house cleaning can happen here. All those bad practices, those cobwebs that have been so hard to clean out, are easily tossed out here.

\section{Paradigm Change}

It is the final step of paradigm revolution. It begins when general consensus is reached on what your paradigm should be. This may occur in upper management, if the whole discipline is tried to search for a new way or new method to find out all the solution or new vista then it is easier to change the paradigm.

\section{Geographical Prognostication}

Harvey (1972) adds Kuhn' (1962) notion of paradigms as universally recognized scientific achievements that for a time provide model problems and solutions to a community of practitioners" - that is, paradigms establish criteria for choosing problems assumed to 
have solutions within accepted rules and conventions. Thus, scientific activity (normal science) is "puzzlesolving" and scientific revolution occurs through accumulation, to the level of crisis, of problems that cannot be solved by reference to a prevailing paradigm. (PEET, 1998)

Ever since David Harvey (1972) paper on revolution the use of the word paradigm has become fashionable in geography as well as having become a pivotal concept for courses in geographic thought on both sides of the Atlantic. Thomas Kuhn, in his classic book, "the Structure of Scientific Revolutions" defined paradigm as 'the entire constellation of beliefs, values, techniques, and so on shared by the members of a given community' (KUHN, 1970). In an earlier articulation of paradigm (the 1962 edition of The Structure of Scientific Revolutions), Kuhn uses this concept in at least 21 different ways (MASTERMAN,1970). These are collapsed into three paradigm types by Masterman: the metaphysical paradigms or metaparadigms, the sociological paradigms and artefact or construct paradigms. Very briefly, the metaparadigms present a global view of science. It is a gestalt view; a Weltanschauung (or map). Such a map, Ritzer wrote, 'Allows the scientist to explore the vast and complex world otherwise impenetrable were been to explore randomly'. Such a paradigm performs three basic functions:

1. It defines what entities are (and are not) the concern of a particular scientific community.

2. It tells the scientific where to look (and where not to look) in order to find the entities of concern to him.

3. It tells the scientist what he can expect to discover when he finds and examines the entities of concern to his field. (RITZER,1975).

It is the broadest area of consensus in a discipline, and it defines the sub areas of research. In contrast, the sociological paradigm is grounded on concrete scientific achievement: a universally recognised scientific achievement. The third and narrowest is the construct paradigm. Here specific entities such as text book, an instrument, or a classic work are viewed as paradigms. Conceptually the construct paradigm is largely subsumed the sociological paradigm and this, in turn, is essentially subsumed in the metaparadigms.

Masterman argues that "if we put what a Kuhnian paradigm is, Kuhn's habit of multiple definitions poses a problem. If we ask, however, what a paradigm does, it becomes clear at once.... That the construct sense of 'paradigm' and not the metaphysical sense of metaparadigm, is the fundamental one. For only with an artefact can you solve puzzles...it remains true that for any puzzle which is really a puzzle to be solved by using a paradigm, this paradigm must be a construct, an artefact, a system, a tool; together with manual of instructions for using it successfully and a method of interpretation of what it does. (HARVEY; HOLLY, 1981)
Robert K. Merton used the term 'Paradigm' to refer a device for codification of an area of sociological analysis. It is an outline of the major concepts, assumptions, propositions, procedures and problems of a theoretical approach in sociological analysis. According to Merton, paradigm gives a qualitative analysis to some of the precision of quantitative analysis. Thus, for some social scientists, there are as many paradigms as there are groups of social scientists (like functionalism, Marxism, phenomenology, symbolic interaction, feminism, post-modernism, etc.), while others use only three paradigms with regard to the major theoretical directions in social sciences, viz., positivist, interpretive and post-positivist or critical (AHUJA, 2001).

Prognostication of natural phenomena and social developments, spatio-temporal changes in existing geographical phenomena is the major concern of Geographical research as noted in different decades. Geographical prognostication includes the following aspects:

1. Prognostications of the social development of space, utilization of natural resources by the society, spatio-temporal changes in natural and social phenomena over space,

2. Development of geographical methods,

3. Development of scientific concepts in geography.

In fact, all the time the development of theoretical and methodological principles of geography are lead by the global and regional needs of growing human society and economy evolving new areas of geographical research about modelling of geographical system,ecological monitoring, geo -techno systems, techno-genic readjustment etc. Anecological approach to geographical researches is evolved due to the struggle for standard of living, continuous industrialization and urbanization, techno-genic restructuring of the natural environment and prevailing processes in terms of Anthropogenic desertification, erosion of landscape, deforestation, atmospheric oxidation of landscape, intensification of cryogenic processes etc.

Geography research attaches to the developing national economy and has brought forth more researches in specialised disciplines - geomorphology, climatology, hydrology, population, settlement, agricultural, industrial, transport, global, environmental geography, regional development and planning and so on.

Emergence of all these geographical disciplines has provoked a prolonged controversy on the subject matter of geography, its structure, methodology and prospects for the development of geographical thought in different period.

\section{Paradigm of Science}

Kuhn advocated that the development of science consists of: Pre-paradigm phase, Professionalization 
phase, Paradigm phase $-\mathrm{I}$, Crisis phase with revolution, Paradigm phase - II, Crisis phase with Revolution, Paradigm Phase - III, and so on.

The development of scientific knowledge looks like a plateau, with some sudden upheavals and abrupt rise followed by smooth and slow progress.

\section{Paradigm of Geography}

The development of geography from the ancient to till date is not a very smooth and continuous process. The period of positive and intellectual progress is interrupted by several periods of regression or stability. This evolution can be explained in light of Kuhn's model. Accordingly, six paradigmatic phases interrupted by six crisis phase can be identified during the whole course of the development of geography till recent times. (RANA, 2008)

Pre-paradigm Phase: scholarly observations of the Eastern and Western civilizations (Ancient phase)

Professionalization phase: concentration of geographical research in the west (ancient phase)

Paradigm Phase I: Periods of Greeks and Romans (up to 500A.D.)

Crisis Phase I: Dark Age in Europe (500-110 A.D.)

Paradigm Phase II: Rise of Arab School of thought (800-1450A.D.)

Crisis Phase II: Age of Discovery (1450-1650)

Paradigm Phase III: Dominance of German school of Thought (1650-1859)

Crisis phase III: Emergence of dualistic tendencies in geography (late 19th century)

Paradigm phase IV: Rise of Determinism (late 19th century-1920s)

Crisis Phase IV: Criticism to Determinism and Paradigmatic shift to Human to physical (early 20th century)

Paradigm phase V: Dominance of French School of thought and rise of Possibilism (the 1930s- W.W.II)

Crisis Phase V: Quantitative Revolution (19401970)

Paradigm Phase VI: Rise of Behaviouralism and Humanistic approaches (1970-the 2000s)

Crisis Phase VI: Methodological Revolutions (computer-based) in 21 st century

\section{Modern Geography and types of research}

Modern geography is actually goal and scientific principles oriented and more concerned with the protection and modification of the environment and increasing effectiveness of the rational management of resources. Consolidation of various geographical disciplines along with the application of geospatial technology in terms of remote sensing technology, Geographical Information System, Global Positioning System etc is actually stimuli for having logical methods and output of geographical researches. In the field of geography, spatial \& temporal analysis, models and mapping are the recent research hotspots.
Thus, changing paradigms in the following types of researches in different decades are noted in:

i) Fundamental or Theoretical or Pure research.

ii) Empirical research.

iii) Diagnostic research

iv) Action-based research

Moreover, relevance, method and application of contemporary traditional geographical approach have been also adversely affected to some extent due to overwhelming recognition and applications of geospatial technology.

\section{Changing Paradigms Since Period of Classical Modern Geography}

Paradigms in Geography and its research are reflected in the following geographical thoughts:

Determinism states that the natural environment is the supreme in determining the behaviour pattern of man on the earth surface, their physical structure, mental ability etc. as reflected in works of Humbold (1769-1859), Ritter (1779-1859), Haeckel (1834-1919), Buckle (1857-1861), Demolins (1852-1907), Frederich Ratzel (1844-1904), Ellen Charchil Semple (1911) and others.

But man has the capability of modifying his environment using existing environmental parameters as reflected in various civilization all over the world. This view has brought about the concept of possibilism as developed by Vidal de La Blache (1950), Jean Brunhes (1920), Isaiah Bowman (1934) and Carl Sauer (1931). According to Possibilism, man is the supreme to create his own surrounding with available resources. But the fact is that human society is helpless before natural calamities - drought, flood, storm surge, tsunami, landslides, earth quakes etc. Keeping this view, new concept-Neo determinism or present-day determinism has been emerged. It is concerned with the causative effect of human efforts. According to the Neo-determinism, Geographical emphasises on social development keeping harmony with nature.

Probabilism is a compromise position between environmentalism and possibilism that assign different probabilities to alternative patterns of geographic behaviour in a particular location or environment

Positivism is dealt with the application of scientific principles and method as drawn from natural and hard science and also social behaviour. Naturalism (the idea or belief that only natural laws and forces, as opposed to supernatural or spiritual ones, operate in the universe.) can also be mentioned in this context.

All these paradigms in geography denote regional inductive approaches. In course of time, these paradigms lost much acceptability due to a lack of scientific approach, inability to transcend the barrier of space, technical practice and ideologies in geography since the mid-nineteenth century.

In view of this, a paradigm shift had occurred evolving Quantitative Geography in 1950 with the aim 
at the statistical analysis of spatial data, development of spatial theory, mathematical models, computerized processing of data etc. So it is marked as the spatial thinking paradigm and the quantitative revolution in geography for the period 1950-1960.This shift includes a shift from descriptive to theoretical approach, consequence and reform of geographical methods into the quantitative realm.

Gradually, such spatial analytical approach (spatial analysis and Spatial Science) had been enriched with geospatial technology (R.S., G.I.S. and G.P.S.) and bring about several research paradigms in geography.

\section{Changing paradigms in Geography with spatial analysis and desirable technology}

The initiation of GIS development in combination with spatially referenced data, spatial data model and data visualization in the mid-1960, computerised mapping, automatic map drafting and use of data format in 1970, computer mapping, capabilities to generate spatial database management system in 1980, map analysis and modelling in 1990, the advent of the web since 2000 integrated GIS and GAS the linked data. All these events are related to geographical paradigms.

Recently, an integrating approach is a new paradigm in geography. The main concern of recent geographical research is the perception of the environment, location and geographical space. Spatial dimension is an important aspect of the social epistemology geography (Science of space). Consideration of space is required to understand the concept of integration and analysis of spatial pattern and processes. The Geoinformatics paradigm in the 21 st century, is actually reflective of the concept of integration in terms of cartography, Geodesy, photogrammetry, spatial analysis, web mapping, global navigation satellite system etc.

In an earlier period, the Mono disciplinary approach in Geography is the single-dimensional traditional paradigm. This paradigm was based on fragmented space (areal differentiation: R. Hartshorne). Interdisciplinary approach is becoming significant in addition to the next phase of a paradigm shift to multidisciplinary which brings many disciplines together. So, practice to analyse the spatial aspects of geographical space initiated at the beginning of the development of scientific geographical concepts. In course time, multidisciplinary or integrated approach towards space replacing mono disciplinary treatment has come into existence recognizing multidimensional spatial, social, environmental and economic reality. The trends say there is a demand of the present time to have a transdisciplinary vision which includes the above all disciplines boundary to formulate a strategy to solve the social unrest which is spreading worldwide. The cliodynamics is considered as a transdisciplinary and the most suitable discipline to describe the unrest and their solutions using the digital datasets of the past. Geographic space is expressed with a set of separate, interdependent relations or interaction forming sustainable multidimensional geographic space.
Multidisciplinary approach provides the basis for the new geographical paradigm referred to as a presently used Geo-informatics paradigm.

But at present, much emphasis is given on the integrated approaches. Interdisciplinary approach is desirable to integrate all possible approaches as concerned with the ecological, economic, technological, political, cultural, dialectic harmony etc. Recognition of geographical space as integrated space gives rise to the foundation new paradigm in geography. It may be called as Choroinformatics. (KOUTSOPOULOS, 2011)

\section{CHANGING PARADIGMS IN PERSPECTIVES OF GEOGRAPHICAL METHOD AND APPROACHES IN DIFFERENT BRANCHES OF GEOGRAPHY}

\section{Paradigm Shift in Cartography}

Cartography as a tool today is more precise and has multiple opportunities for research regarding the spatial organization of geographical features (Jha, 2016). The specialization of content in maps and contemporary technological options are complementary to each other. Varying Publications of thematic maps also indicate paradigmatic changes in Cartography.

In cartography, the following three paradigm shifts may be marked:

- 1st Paradigm Shift introducing Remote Sensing, G.I.S. and Digital data

- 2nd Paradigm Shift with digitization in a wider range

- 3rd Paradigm Shift with the transition between cartographic print and digitization.

- 4th Paradigm Shift with the transition between Geography and Digitalization.

\section{Paradigm Shift in Geomorphology}

Paradigm shift in Geomorphology had taken places through the wider range of quantification of geomorphic analysis (Statistical and Mathematical) replacing prolong dominant evolutionary approach (cyclic erosion) based paradigm (Chart 1). Emergence of non-cyclic equilibrium concepts and application of G.I.S. leads to shifting in the existing paradigm.

Geomorphological mapping is significant in understanding earth surface processes, geochronology, natural resources, natural hazards and landscape. It involves the classification of the terrain into the conceptual spatial units on the basis of morphology, composition and structure, chronology, environmental system-land cover, soil, ecology as well as the spatial topological relationship of surface features. Now spatio-temporal data, geo computational approaches are useful for the quantitative characterization of landscape morphology and the integration of varying landscapes 
thematic information. A large number of conceptual, theoretical and information technology issues are at center of digital geomorphological mapping. Analysis of geomorphic units through landform element models and the landform pattern model, developments in numerical modeling of surface processes have also enriched the applied geomorphology.
Environmental protection and management have brought about new paradigms in applied geomorphology and environmental geography with interdisciplinary as well as integrated approaches (Scientific, humanistic and environmental systems).

Chart 1 - The Major Landmarks In Geomorphology.

\begin{tabular}{|c|c|}
\hline 1788 & Hutton's Theory of the Earth \\
\hline 1802 & Playfair's Illustrations of the Huttonian theory of the Earth \\
\hline 1815 & William Smith: Superposition and Correlation by Fossils \\
\hline 1830 & Lyell's Principles of Geology \\
\hline 1840 & Agassiz; the Glacial Theory \\
\hline 1859 & Darwin's On the Origin of Species Evolution \\
\hline 1875 & Powell's Exploration of the Colorado River of the West and Its Tributaries \\
\hline 1877 & Gilbert's Report on the Geology of the Henry Mountains \\
\hline Mid 1880s & Term 'Geomorphology' Introduced \\
\hline 1888 & Suess: the Concept of Eustasy \\
\hline 1899 & Davis Proposes the Erosion Cycle \\
\hline 1909 & Davis Geographical Essays, Penck and Bruckner Model \\
\hline 1912 & Wegner's Continental Drift \\
\hline 1914 & Gilbert's Transportation of Debris by Running Water \\
\hline 1924 & Walther Penck's Morphological Analysis of Landforms (in German) \\
\hline 1928 & Baulig: the Origin of Denudation Chronology \\
\hline 1938 & W.M. Davis's Last Publication \\
\hline 1941 & Bagnold's Physics of Blown Sand and Desert Dunes \\
\hline 1945 & Horton: Drainage Basin Morphometry and the Origin of Quantification \\
\hline 1950 & Strahler: Early Application of Statistics, L.C.King's Pediplanation Theory \\
\hline 1953 & Penck's Morphological Analysis of Landforms (English Translation) \\
\hline 1955 & Wooldridge and Linton Denudation Chronology Reaches Its Peak \\
\hline 1960 & $\begin{array}{l}\text { Approximate Date for the End of the Erosion Cycle and Denudation } \\
\text { Chronology }\end{array}$ \\
\hline 1962 & $\begin{array}{l}\text { Kuhn Introduces the Term 'Paradigm', Chorley: Geomorphology and } \\
\text { Systems Theory; Early Use of Term 'Plate Tectonics' }\end{array}$ \\
\hline 1964 & Leopold, Wolman and Miller's Fluvial Processes in Geomorphology \\
\hline 1965 & A Large Number of Statistical Concepts Introduced between 1960 and 1965 \\
\hline 1966 & Manley Writes of the 'New Geography' \\
\hline 1967 & Chorley and Haggett's Models in Geography \\
\hline 1969 & Chorley's Water, Earth and Man \\
\hline 1970 & $\begin{array}{l}\text { Applied Studies begin to Multiply Noticeably, Craik's 'Environmental } \\
\text { Psychology', on Perception }\end{array}$ \\
\hline 1971 & Chorley and Kennedy's Physical Geography: A System Approach \\
\hline 1972 & The 'New Geology' (Plate Tectonics) Well Established \\
\hline 1974 & Cooke and Doorkamp's Synthesis of Applied Studies in Geomorphology \\
\hline 1976 & Whalley's Properties of Materials and Geomorphological Explanation \\
\hline 1980 & Coates and Vitek's Thresholds in Geomorphology \\
\hline $1980-83$ & Man-Environment Studies Come to the Fore. \\
\hline
\end{tabular}
Source: the authors

Changing paradigms in Environmental Geography

In the context of the global, national environmental issues, integrated evaluation in the following aspects with geospatial databased mapping in different dimensions in recent decades as started with the works by Coats (1971) is the reflection of paradigmatic changes.

1. Biophysical environment, natural resources, ecotone zones, their fringes, landforms,

2. Biosocial environment, human population, its composition, migration 
3. interface of man and environment socioeconomic and political processes-socio economic and political processes-governance and geopolitics of the environment

4. Urbanization and regional disparities; secondary and tertiary economic activities, space time rhythms and metropolitan areas and spatial organization

5. Humanistic studies of slums and pollution

6. Human impact on the natural environment

7. Degradation of environment and desertification

8. Air-water- Noise pollution

9. Environmental hazards and disaster

10. Population and ecological crisis

11. Conservation of natural resources

12. Management of environment, environmental impact assessment and eco Auditing, Biodiversity 13. Sustainable development

14. Environmental ethics and legislation and planning and others

Approaches to the environmental geography are involved with two methods, such as Systematic Geography and Regional Geography with the advent of Geospatial technology (Scientific Geographic Method and Humanistic Geographic Method).

\section{Scientific geographic method}

i) An empirical approach to environmental resources with their spatial distribution

ii) Structural approach with satellite imageries and aerial photographs

iii) An ecosystem approaches

iv) A system approach with concepts entropy, order, information, growth etc.

Humanistic Geographic method

i) Phenomenological approach to study life world

ii) Evaluating Approach

iii) A structural approach to study role the of society within a structure and environment.

\section{Changes in the paradigm of Behavioural Geography}

Behavioural geography (Humanistic) with new interdisciplinary ties another reflection of the paradigm changes with the newness in approaches. It deals with the human activities in space, place and environment at the level individual in perspectives of dynamic and bidirectional changing and ongoing humanenvironment interactions. It is also concerned with the cartography, market and census related information.

It has interdisciplinary outlets - linguistic, anthropology, economics, environmental disciplines. planning, architecture etc. The integration of the following approaches are noted in this regard:

a. Territoriality approach to study spatial organization,

b. Positivistic technocratic approach and c. Convert behaviour of mental constructs.

\section{Health Geography}

Quantitative geographical approaches to health research in combination with environmental determinant, health behaviour, environmental exposures and interactions between the individual and environmental mechanism of disease, individual perceptions of place, perception of social cohesion, access to available food and othersall these humanistic perspectives have got much momentum over the world.

Advancement in the capabilities and accessibility of GIS, GPS, spatial statistics, accessible placebased computational model and analytical tools in geography has brought a new paradigm in health geography as well as representation in the representation of location oriented human perceptions, experience and interaction with the environment.

\section{Urban Geography and regional planning}

Present-day comprehensive evaluation of city structure and urban dynamics characterisation of spatial arrangement for urban land use, land use pattern are getting more popularity. Urban geography contributes planning paradigms to the present conditions of Indian cities, the evolution of the morphology of city core, etc.

Evolutionary shift has taken place from Geographic Information System to urban analytic to represent urban data. In addition, quantitative land changing modeling approaches -descriptive, predictive and planning models also have contributed in this regard

Evolution of regional planning and regional development theories can be done through:

i. Early approaches based on resource development and environmental preservation

ii. Welfare regionalism and

iii. New regionalism for spatial planning

\section{Globalization in research application}

There is a shifting in research aptitude too. Now a day's, research in any field has a strong focus on the application aspects. Whatever the field, scale and aim are concerned, any research tries to put emphasis on its application and benefits to a larger scale, towards the welfare of the society and above all for sustainability. For this new trend, the researchers make a soft swift from pure to applied perspective. This is how a microlevel research being globalized by providing solutions to a larger population.

\section{Role of New paradigms in the recent decade}

Such Comprehensive framework in geographical research may be helpful to generate inputs desirable for national and global targets-sustainable development goals as a part of the 2030 agenda for sustainable development - 
No poverty, Zero Huger, Good health and well being, Quality education, Gender equality, Clean water and sanitation, affordable and clean energy, Decent work and economic growth, Industry-Innovation \& infrastructure, reduced inequality, sustainable cities and communities, responsible consumption and production, Climate Action, Life below water, life on land, Peace, Justice, Strong Institution, and Partnership on Goal.

\section{CONCLUSION}

Geography, itself is a subject of multi-dimensions from the very beginning. As the society and education system was evolved, each and every dimension flourished separately with its own endeavour. But a strong linkage is always established showing its interdisciplinary trends. Later on, with specializations in its branches, geography started its research in association with other branches introducing multidisciplinary projects. Now with the advent of technology and evolution of the philosophical thought process, we are on the threshold of transdisciplinary paradigm excluding the boundary of the individual subject.

Hence, this paradigm shift also encourages dataintensive spatial analysis as enriched by a large volume of geo-coded data, radical approaches to quantitative geography and changing paradigms in geospatial technology.

\section{REFERENCES}

Ahuja, R. Research Methods. Jaypur: Rawat Publications, 2001.

Bowman, I. Geography in Relation to Social

Science. New York: C. Scribners Son, 1934.

Brunhes, J. Human Geography. Chicago: Rand Macnally \& Co., 1920.

Coates, D.R. Introduction to Environmental Geomorphology. In:

Environmental Geomorphology. Binghamton: State University of New York, 1971. pp-5-6.

Harvey, D. Revolutionary and Counter Revolutionary Theory in Geography and the
Problem of Ghetto Formation. Antipode, v. 4, n.2, 1972. https://doi.org/10.1111/j.14678330.1972.tb00486.x

Harvey, M.E.; Holly, B.P. Themes in Geographical Thought. New York: Routledge, 1981

Jha , V.C. Cartography for the Analysis and Management of Climate Change. Indian Cartographer, v. 36, 2016. pp. 1-3

Koutsopoulos, K.C. Changing Paradigms of Geography. European Journal of Geography, v. 1, 2011. pp-54-75

Kuhn, T. The structure of scientific revolutions. Chicago: The University of Chicago Press, 1962.

Kuhn, T. The structure of scientific revolutions. 2 ed. Chicago: The University of Chicago Press, 1970.

Masterman, M. The Nature of a Paradigm. In LAKATOS, I.; Musgrave, A. (Eds.). Criticism and the Growth of Knowledge: Proceedings of the International Colloquium in the Philosophy of Science. Cambridge: Cambridge University Press, 1965. pp. 59-90. https://doi.org/10.1017/CBO9781139171434.0 08

Peet, R. Modern Geographical Thought. Hoboken: Blackwell Publishers Limited, 1998.

Rana, L. Geographical Thought New Delhi : Concept Publishing Company, 2008.

Ritzer, G. Sociology: A Multiple Paradigm Science. Boston: Allyn and Bacon, 1974.

Sauer, C. O. Cultural Geography. Encyclopedia of the Social Sciences, v. 6, 1931. pp. 621-624

Vidal de La Blache, P. Principles of Human Geography. London: Constable Publisher, 1950.

\section{AUTHORS CONTRIBUITION}

Koyel Paul and Vibhash Chandra Jha contributed in Conceptualization, Methodology and Writing - revision and editing. 